\title{
Serum screening in first trimester to predict pre-eclampsia, small for gestational age and preterm delivery: systematic review and meta-analysis
}

\author{
Yan Zhong, Fufan Zhu and Yiling Ding ${ }^{*}$
}

\begin{abstract}
Background: Early assessment before the establishment of placental dysfunction has the potential to improve treatment and prognosis for clinical practice.The objective of the study is to investigate the accuracy of serum biochemical markers(Pregnancy- Associated Plasma Protein-A (PAPP-A), human Chorionic Gonadotropin (hCG), Placental Growth Factor (PIGF), Placental Protein 13 (PP13) used in first trimester serum screening in predicting preelampsia, small for gestational age (SGA) and preterm delivery.
\end{abstract}

Methods: The data sources included Medline, Embase, Cochrane library, Medion, hand searching of relevant journals, reference list checking of included articles and contact with experts. Two reviewers independently selected the articles. Two authors independently extracted data on study characteristics, quality and results.

Results: The results showed low predictive accuracy overall. For preeclampsia, the best predictor was PIGF; $L R+4.01(3.74,4.28)$, $L R-(0.67,0.64,0.69)$. The predictive value of serum markers for early preeclampsia was better than that of late preeclampsia. For SGA the best predictor was PP13; LR+ $3.70(3.39,4.03)$, LR- $0.70(0.67,0.73)$. For preterm delivery, the best predictor was PP13; LR+ $4.16(2.72,5.61)$, LR- $0.56(0.45,0.67)$.

Conclusion: First trimester screening analytes have low predictive accuracy for pre-eclampsia, small for gestational age and preterm delivery. However, the predict value of first trimester analytes is not worse than that of the second trimester markers.

\section{Background}

Preeclampsia, fetal growth restriction (FGR) and preterm delivery are major contributors to perinatal mortality and morbidity. They not only alter the immediate outcomes of pregnancy at the time of delivery but also the long-term cardiovascular health of the affected women and children. For example, a history of preeclampsia increases a female's risk of myocardial infarction, stroke or diabetes mellitus by two to eight fold over the next two decades [1]. Moreover, newborns diagnosed with FGR at birth have a two to eight fold increased risk for hypertension, cardiovascular disease, diabetes mellitus or renal disease as adults $[2,3]$.

\footnotetext{
* Correspondence: dylcsu@sina.cn

The Second Xiangya Hospital, Central South University, No.139, Middle Renmin Road, Changsha, Hunan 410011, P.R. China
}

Recent evidence suggests that the underlying pathology of preeclampsia, FGR and preterm delivery takes place in the first trimester. Earlier assessment before the establishment of placental dysfunction may have the potential to improve treatment and prognosis for clinical practice. Numerous stutdies have shown that abnormal concentration of first trimester serum markers is related to the onset of preeclampsia, small for gestational age and preterm delivery. With the increased use of firsttrimester screening for Down syndrome, there is the opportunity to 'piggy back' screening tests for preeclampsia, FGR and preterm delivery onto existing tests.

The purpose of our review was to investigate the accuracy of serum biochemical markers (PregnancyAssociated Plasma Protein-A (PAPP-A), human Chorionic Gonadotropin (hCG), Placental Growth Factor (PlGF), Placental Protein 13 (PP13) used in first trimester serum 
screening in predicting preelampsia, small for gestational age (SGA) and preterm delivery. We systematically reviewed the available literature and meta-analysed the data.

\section{Methods}

\section{Identification of studies}

We searched MEDLINE, EMBASE and Cochrane Library from inception to April 2014 for relevant citations. The reference lists of all known primary and review articles were examined to identify cited articles not captured by electronic searches. The search strategy consisted of $\mathrm{MeSH}$ (medical subject heading) terms, Emtree terms, and keywords related to the disease (preeclampsia, small for gestational age, preterm birth, preterm delivery, etc.) combined with serum markers(PAPP-A, hCG, PP13, PlGF, etc.). Details of the search strategy are available from the authors. Language restrictions were not applied. A comprehensive database of relevant articles was constructed.

\section{Study selection}

The first stage of study selection was the scrutinizing of the database by two reviewers to identify articles from title and/or abstract. In a second stage, a search based on keywords for each of the analytes under review was performed within the Reference Manager database. The results of this search were scrutinized by a second reviewer. In the final stage of study selection the full papers of identified articles were obtained with final inclusion or exclusion decisions made after independent and duplicate examination of the papers. We included studies that reported on singleton pregnancies at low risk in any healthcare setting before the $14^{\text {th }}$ week of gestation. Test accuracy studies allowing generation of $2 \times 2$ tables were included.

\section{Data extraction and study quality assessment}

Acceptable reference standards for preeclampsia were: persistent systolic blood pressure $\geq 140 \mathrm{mmHg}$ or diastolic blood pressure $\geq 90 \mathrm{mmHg}$ with proteinuria $\geq 0.3 \mathrm{~g} / 24 \mathrm{~h}$ or $\geq 1+$ dipstick (= $30 \mathrm{mg} / \mathrm{dl}$ in a single urine sample), new after 20 weeks of gestation. Early preeclampsia was defined as preeclampsia resulting in a delivery before 34 weeks of gestation. Late preeclampsia was defined as preeclampsia resulting in a delivery after 34 weeks of gestation. Acceptable reference standards for SGA included birth weight $<10^{\text {th }}$ centile adjusted for gestational age and based on local population values. We also included severe SGA defined as birth weight $<5^{\text {th }}$ centile. Preterm delivery was defined as delivery $<37$ weeks. We also included preterm delivery $<34$ weeks.

All included manuscripts were assessed by at least one reviewer for study and reporting quality using validated tools. Items considered important for a good quality paper were prospective design with consecutive recruitment, prospective design, adequate description of selection criteria, patient spectrum,test and use of appropriate reference standard.

\section{Data synthesis and analysis}

From the $2 \times 2$ tables the following were calculated with their $95 \%$ confidence intervals for individual studies; sensitivity (true positive rate), specificity (true negative rate) and the likelihood ratios (LR). Results were pooled among groups of studies with similar characteristics, the same threshold and same adverse outcomes. Where $2 \times 2$ tables contained zero cells, 0.5 was added to each cell to enable calculations. All statistical analyses were performed using Stata 11.0 statistical package.

\section{Results}

Literature identification and study quality

Figure 1 summarises the process of literature identification and selection. There were 1575 primary articles that met the selection criteria. The initial electronic search strategy led to screen titles and abstracts of 1406 citations. Fig. 1 shows the screening and selection process that was followed for the identification and inclusion of studies. We retrieved 155 potentially eligible primary studies for detailed evaluation and inclusion in the systematic review, and an additional 14 potentially eligible publications from the reference lists of included studies. Detailed evaluation led to the exclusion of 66 publications that did not meet the selection criteria. Overall, 103 studies were considered relevant and were included in the systematic review. Total number of women in 103 studies is 432,621 .

The quality assessment of included studies is summarized in Fig. 2. There was good reporting of prospective design with consecutive recruitment, prospective design, adequate description of selection criteria, patient spectrum, test and use of appropriate reference standard.

\section{Data analysis}

For both analysis for preelampsia, SGA and preterm delivery, there was significant heterogeneity in all results. As a consequence of this the random effects model was used throughout the study.

\section{Pregnancy associated plasma protein A (PAPP-A)}

The results for PAPPA to predict preeclampsia are summarized in Fig. 3. The total number of women in these studies is 385,643 . There were 16 studies for preeclampsia, 10 for early preeclampsia and 3 for late preeclampsia included in the meta-analysis [4-22]. For preeclampsia, thresholds that were most commonly used were $<5^{\text {th }}$ centile ( 5 studies) and $<10^{\text {th }}$ centile ( 4 studies). The most accurate predictor was PAPPA $<0.4 \mathrm{MoM}$ (multiples of median); LR+ 2.17 (1.48,3.17), LR- 0.91 (0.85, 


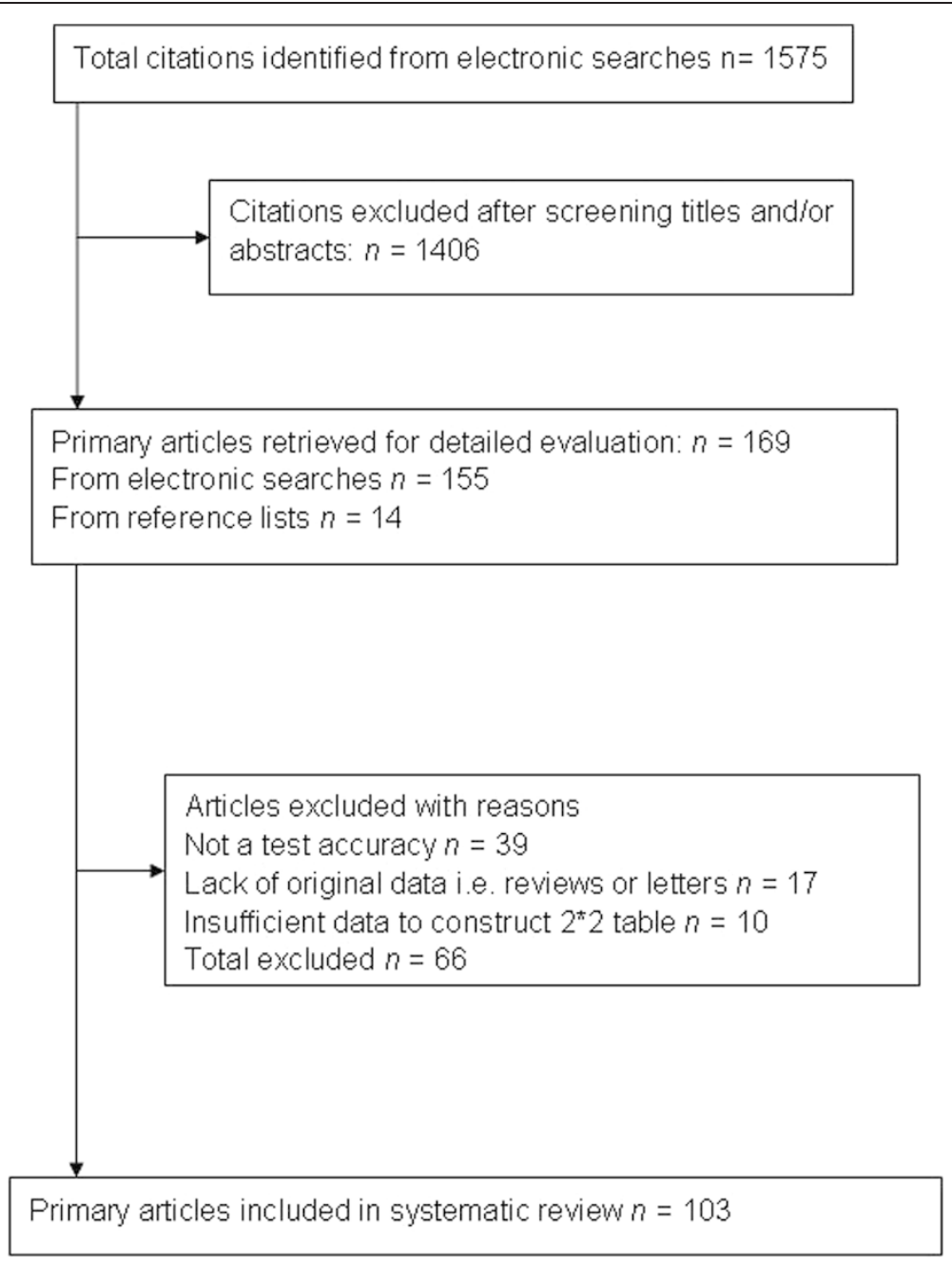

Fig. 1 Seletion process: process from initial search to final inclusion for biochemical screening to predict pre-eclampsia/small for gestational age/preterm delievery

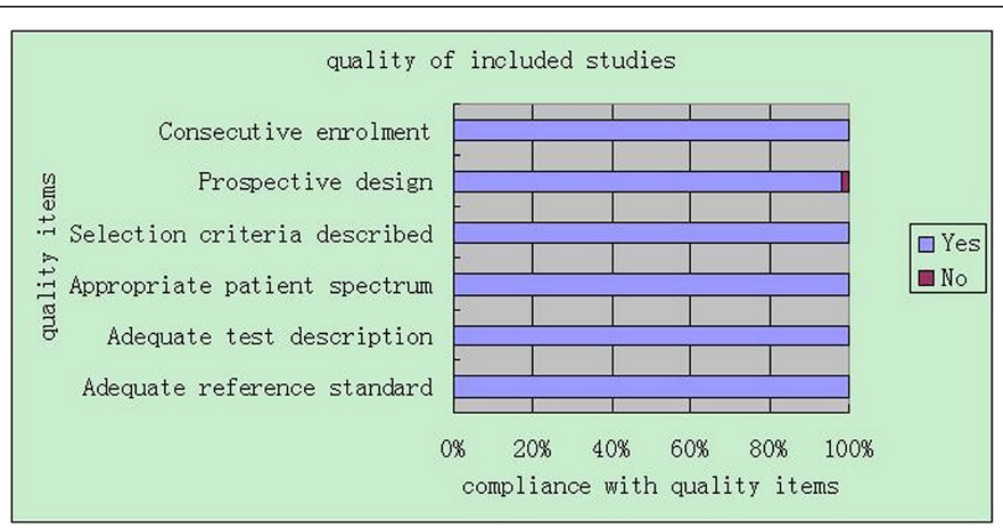

Fig. 2 Study quality: bar chart showing quality of evidence on first trimester biochemical screening markers to predict pre-eclampsia, small for gestational age and preterm delivery 


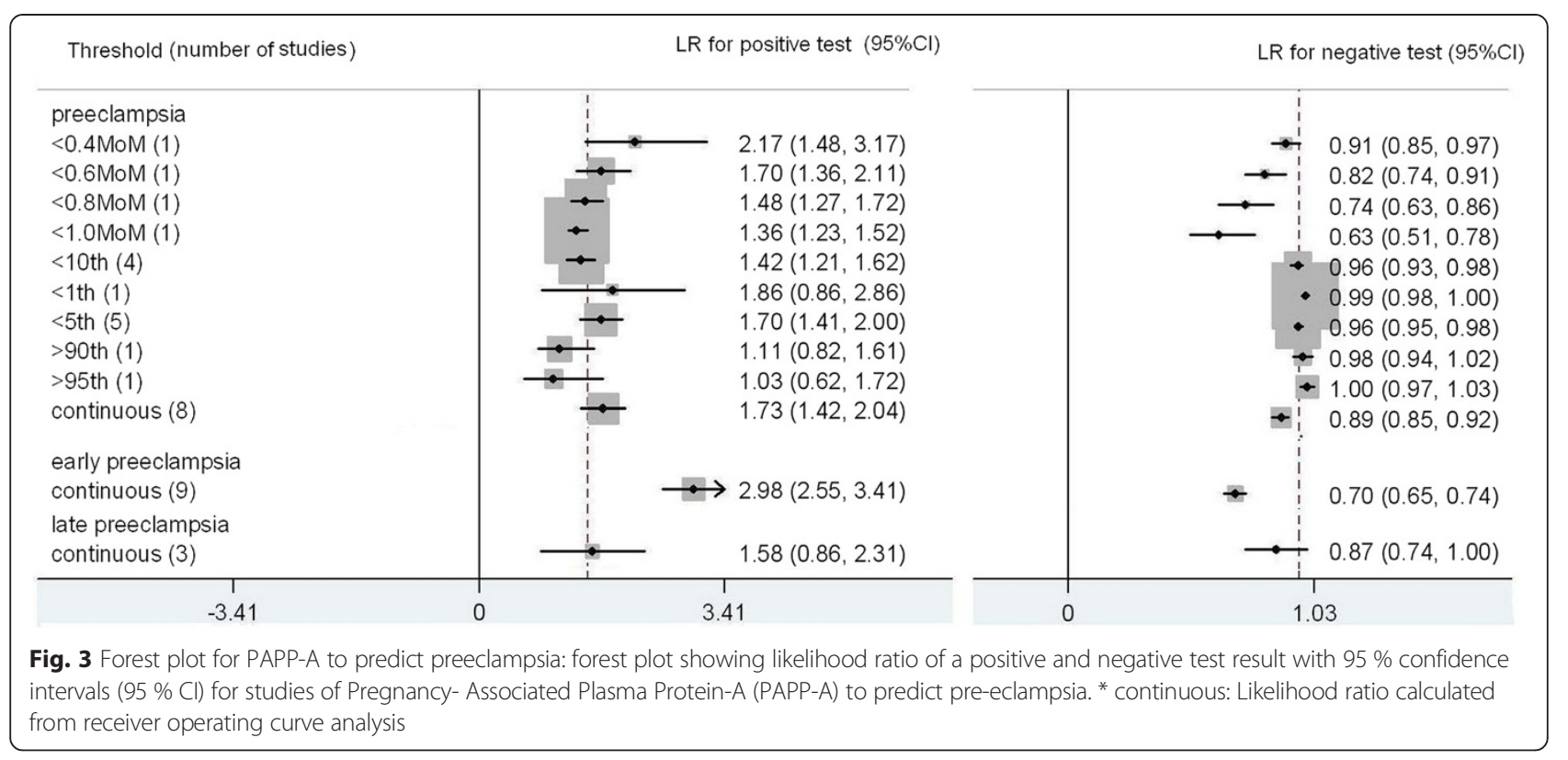

0.97), sensitivity $16 \%$ (4\%, $35 \%$ ), specificity $93 \%$ (76\%, $99 \%)$, this was a single study. For early preeclampsia, all the predictive value was calculated from receiver operating curve analysis. The predictive value for early preeclampsia (LR+ $2.98(2.55,3.41)$, LR-0.70 $(0.65,0.74)$, sensitivity (39\% $(33 \%, 47 \%))$, specificity (87\% (82\%, $90 \%))$ was generally better than that for preeclampsia and late preeclampsia $(\mathrm{LR}+1.58(0.86,2.31)$, LR-0.87 $(0.74,1.00)$, sensitivity $29 \%$ (28\%, $30 \%)$, specificity $82 \%(81 \%, 83 \%))$.
For SGA there were 19 studies for $\mathrm{SGA}<10^{\text {th }}$ centile and 6 studies for $\mathrm{SGA}<5^{\text {th }}$ centile included in the meta-analysis [4, 6, 7, 10, 11, 23-36] (Fig. 4). The commonest threshold used to predict $\mathrm{SGA}<10^{\text {th }}$ centile were PAPPA $<5^{\text {th }}$ centile ( 9 studies). The best predictor for SGA $<10^{\text {th }}$ centile was PAPPA $<1^{\text {st }}$ centile; LR +3.59 (2.77, 4.40), LR- 0.98 (0.97, 0.98), sensitivity $3 \%$ (3\%, $4 \%)$, specificity $99 \%(98 \%, 99 \%)$. For SGA $<5^{\text {th }}$ centile, PAPPA $<1^{\text {st }}$ centile was also the most accurate predictor,

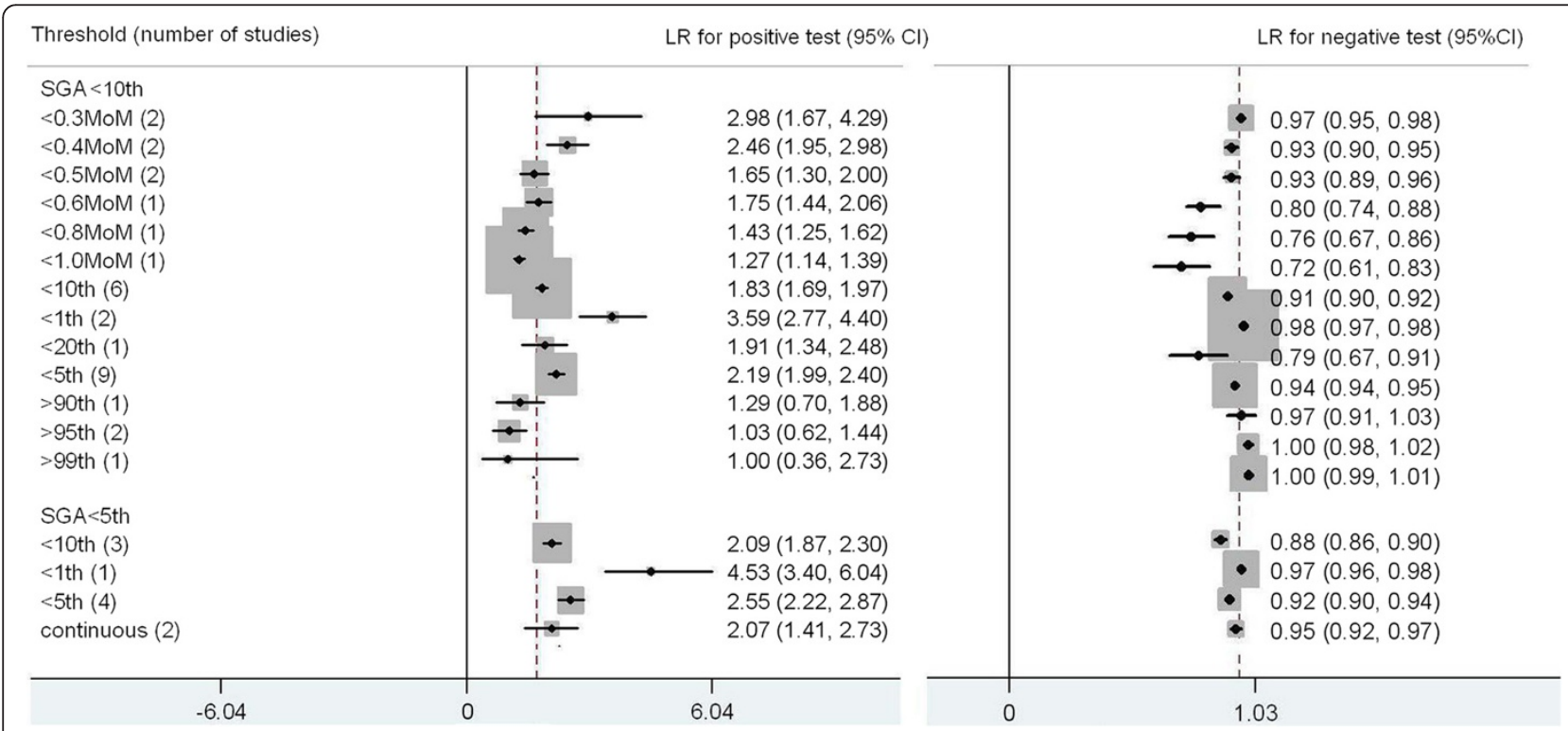

Fig. 4 Forest plot for PAPP-A to predict SGA: forest Plot showing likelihood ratio of a positive and negative test result with $95 \%$ confidence intervals (95\% CI) for studies of Pregnancy- Associated Plasma Protein-A (PAPP-A) to predict small for gestational age (SGA). * continuous: Likelihood ratio calculated from receiver operating curve analysis 
LR+ $4.53(3.40,6.04)$, LR-0.97 $(0.96,0.98)$, sensitivity $4 \%$ (2\%, $5 \%)$, specificity $99 \%$ (98\%, $100 \%)$.

For preterm delivery there were 12 studies for preterm delivery and 6 studies for preterm delivery $<34$ weeks included in the meta-analysis $[4,7,10,11,23-25,33,35,37-40]$ (Fig. 5). The commonest threshold used to predict preterm delivery were $<5^{\text {th }}$ centile ( 6 studies). The best predictor for preterm delivery was calculated from receiver operating curve analysis; LR+ 2.99 (1.95, 4.03), LR- $0.66(0.60,0.77)$, sensitivity $44 \%$ (28 \%, $58 \%)$, specificity $85 \%$ (70 \%, $93 \%)$. For preterm delivery < 34 weeks, PAPPA $<0.3$ MoM was the most accurate predictor, LR+ 3.64 (1.89, 7.02), LR-0.96 $(0.93,1.00)$, sensitivity $5 \%$ (1\%, $14 \%)$, specifcity $99 \%$ (93\%, $100 \%)$.

\section{Plancenta protein 13 (PP13)}

The results for PP13 are summarized in Fig. 6, all the predictive value was calculated from receiver operating curve analysis. The total number of women in these studies is 60,786 . For early preeclampsia there were 6 included studies $[8,12,15,41-44]$. PP13 turns out to be more accurate predictor for early preclampsia; LR+ 4.20 $(3.69,4.71)$, LR-0.60 $(0.53,0.66)$, sensitivity $47 \%$ (39\%, $54 \%)$, specificity $89 \%(85 \%, 91 \%)$. For preeclampsia there were 4 studies $[8,21,45,46]$; $L R+2.69(2.05,3.32)$, LR- $0.51(0.42,0.59)$, sensitivity $60 \%$ (50\%, $73 \%)$, specificity $78 \%(64 \%, 85 \%)$. For SGA $<10^{\text {th }}$ there was only one included study[29], LR+ 3.70 (3.39, 4.03), LR- 0.70 (0.67, 0.73), sensitivity $36 \%(33 \%, 41 \%)$, specificity $90 \%$ (88 \%, $92 \%)$. For preterm delivery, there were 2 included studies [39, 45]; LR+ $4.16(2.72,5.61)$, LR- 0.56
(0.45, 0.67), sensitivity $51 \%(37 \%, 66 \%)$, specificity $88 \%$ (76\%, $93 \%)$.

\section{Placental growth factor (PIGF)}

The results for PlGF are summarized in Fig. 7. There were 16 included studies. The total number of women in these studies is 84,424 . For preeclampsia there were 2 studies [13, 20]; LR + 4.01(3.74, 4.28), LR-0.67 (0.64, $0.69)$, sensitivity $40 \%(37 \%, 43 \%)$, specificity $90 \%$ (88\%, $91 \%)$. PlGF was also shown to be more predictive for early preeclampsia[12-14, 17, 19, 20]; LR + 6.05 (5.55, 6.55), LR- 0.48 (0.43, 0.52), sensitivity $56 \%$ (52\%, $61 \%)$, specificity $91 \%$ (89\%, $92 \%)$. For SGA there were 2 included studies [29, 32]; LR+ 2.65 (2.09, 3.20), LR-0.81 $(0.77,0.85)$, sensitivity $27 \%(20 \%, 36 \%)$, specificity $90 \%(83 \%, 94 \%)$.

\section{Human chorionic gonadotrophin (hCG)}

The results for hCG to predict preeclampsia are summarized in Fig. 8. The total number of women in these studies is 112,400 . There were 4 included studies in the meta-analysis [7, 10, 11, 18], and there was single study for every threshold. The most accurate predictor was hCG < 0.6MoM; LR+ 1.41 (1.10, 1.82), LR- 0.90 (0.82, 0.99 ), sensitivity $28 \%$ (2\%, $71 \%$ ), specificity $80 \%$ (36\%, $99 \%)$. There were 2 studies and 1 study looking at early preeclampsia [18, 19] and late preeclampsia [19] respectively as the outcome, results showed no improvement in prediction.

For $\mathrm{SGA}<10^{\text {th }}$ centile there were 9 included studies in the meta-analysis [7, 11, 23-25, 29, 30, 35, 36] (Fig. 9).

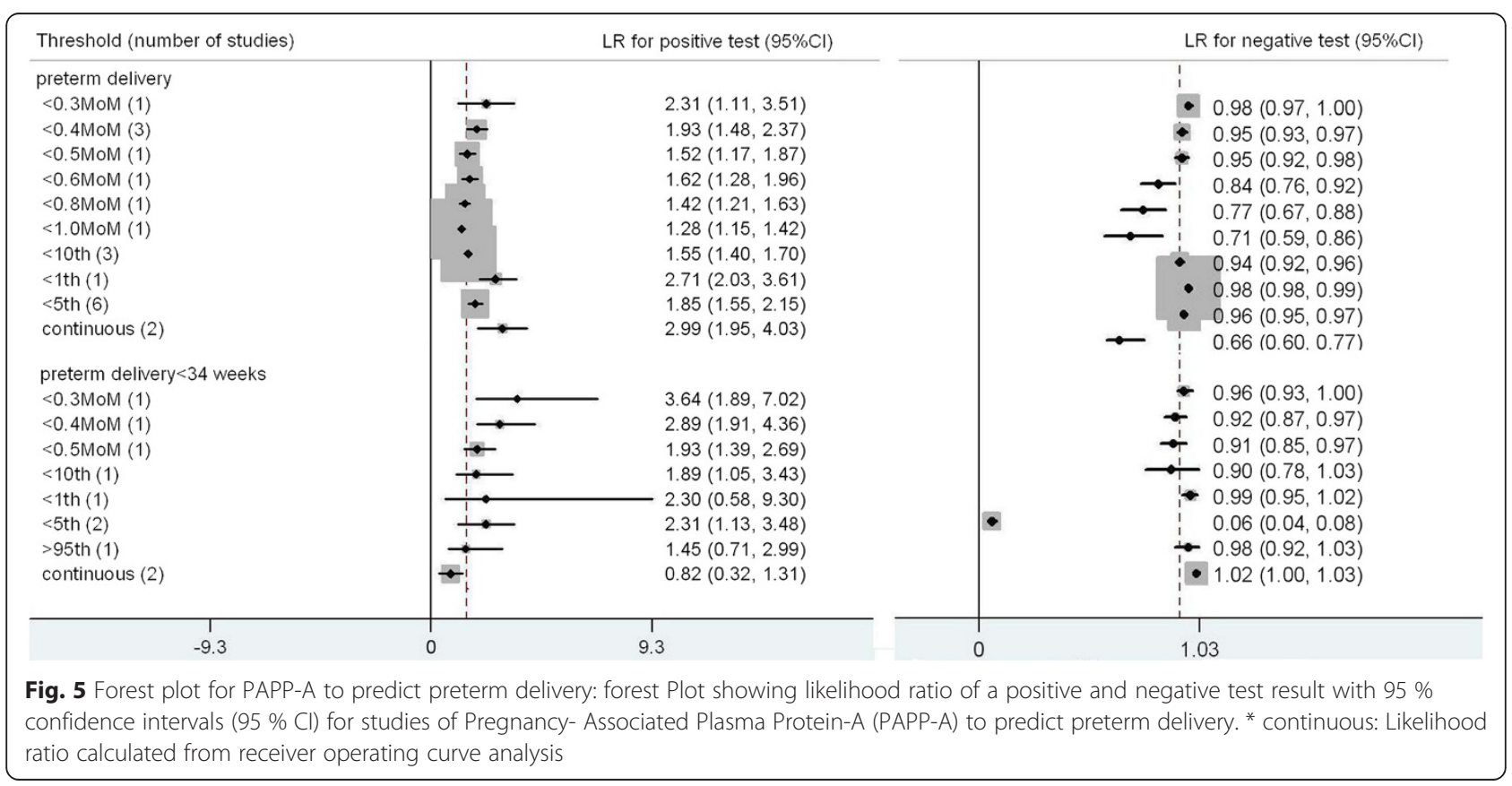




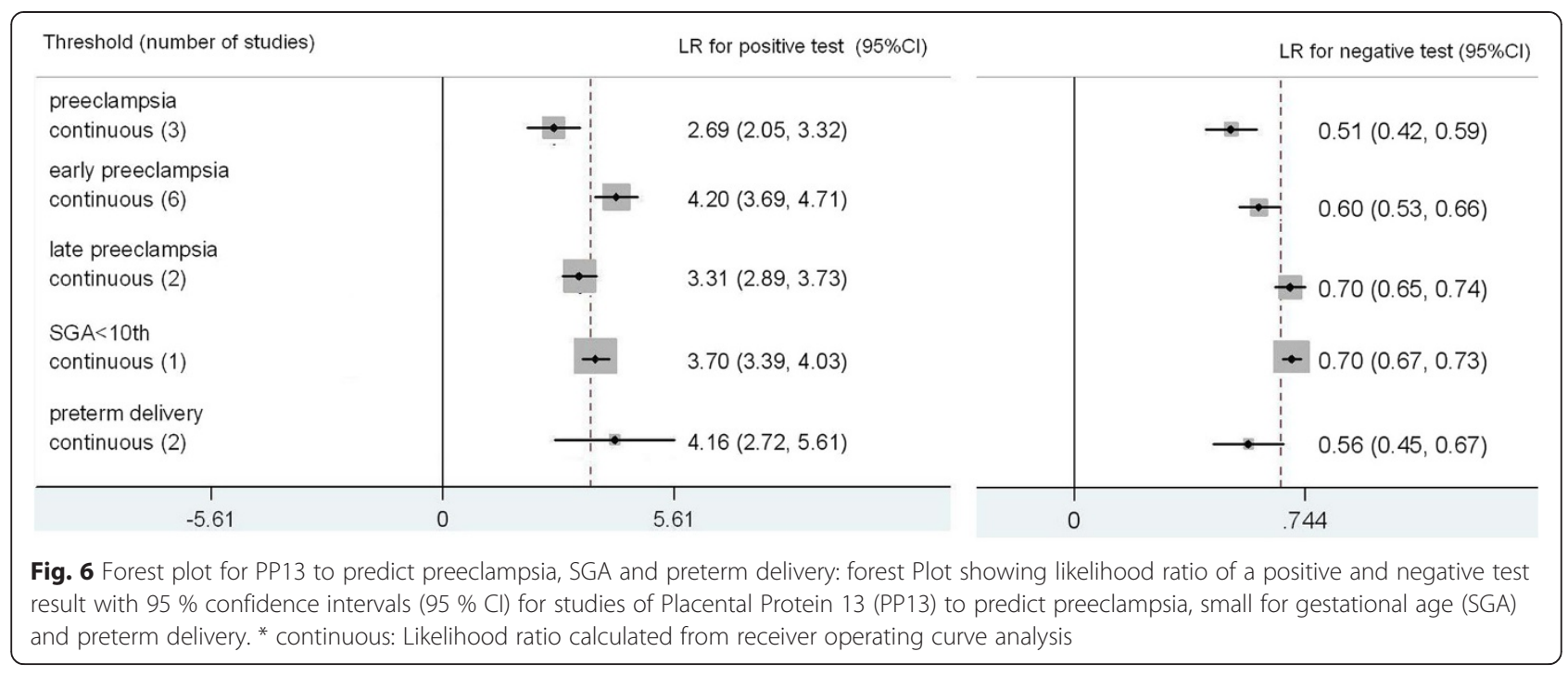

The commonest thresholds used were $\mathrm{hCG}<5^{\text {th }}(3$ studies) and calculated from receiver operating curve analysis. The most accurate predictor for $\mathrm{SGA}<10^{\text {th }}$ centile was calculated from receiver operating curve analysis; LR+ $3.44(3.26,3.63)$, LR-0.73 $(0.71,0.74)$, sensitivity $34 \%$ (32\%, $37 \%)$, specificity $90 \%$ (89\%, $91 \%)$. For SGA $<5^{\text {th }}$ centile there were only 2 thresholds studied with single study for each $[7,10], \mathrm{hCG}<10^{\text {th }}$ centile was more accurate; LR+ $2.86(1.97,4.16), \mathrm{LR}-0.90(0.85$, 0.96), sensitivity $15 \%$ (5\%, $26 \%)$, specificity $95 \%$ (87\%, $100 \%)$.

There were 6 studies for preterm delivery [7, 10, 11, $23,35,40]$ and 4 studies for preterm delivery < 34 weeks $[7,23,25,40]$ included in the meta-analysis (Fig. 10). The commonest threshold used to predict preterm delivery were $\mathrm{hCG}<5^{\text {th }}$ centile ( 6 studies). The best predictor for preterm delivery was hCG $<0.5$ MoM; LR+ 2.71 $(1.88,3.54)$, LR- $0.92(0.89,0.96)$, sensitivity $12 \%$ (5\%, $21 \%)$, specificity $96 \%$ (89\%, $98 \%)$. For preterm delivery
$<34$ weeks, hCG $>95^{\text {th }}$ was the most accurate predictor, LR+ $1.74(1.22,2.47)$, LR-0.96 $(0.93,0.99)$, sensitivity $9 \%$ (2\%, $29 \%)$, specificity $95 \%$ (76\%, $99 \%)$.

\section{Discussion}

We evaluated the accuracy of five serum screening markers commonly used in first trimester screening for preeclampsia, SGA and preterm delivery. The results showed low predictive accuracy overall. For preeclampsia, the best predictor was PlGF. However, it is important to point out that this threshold was determined from a receiver operating characteristic curve and based only 2 studies. For early and late preeclampsia, the best predictor was also PIGF. Generally, the predictive value of serum markers for early preeclampsia is better than that of late preeclampsia. For SGA the best predictor overall was PP13 while PAPPA $<1^{\text {st }}$ centile was the best predictor of SGA $<5^{\text {th }}$ centile. These results were both based on single studies. For preterm delivery, the best

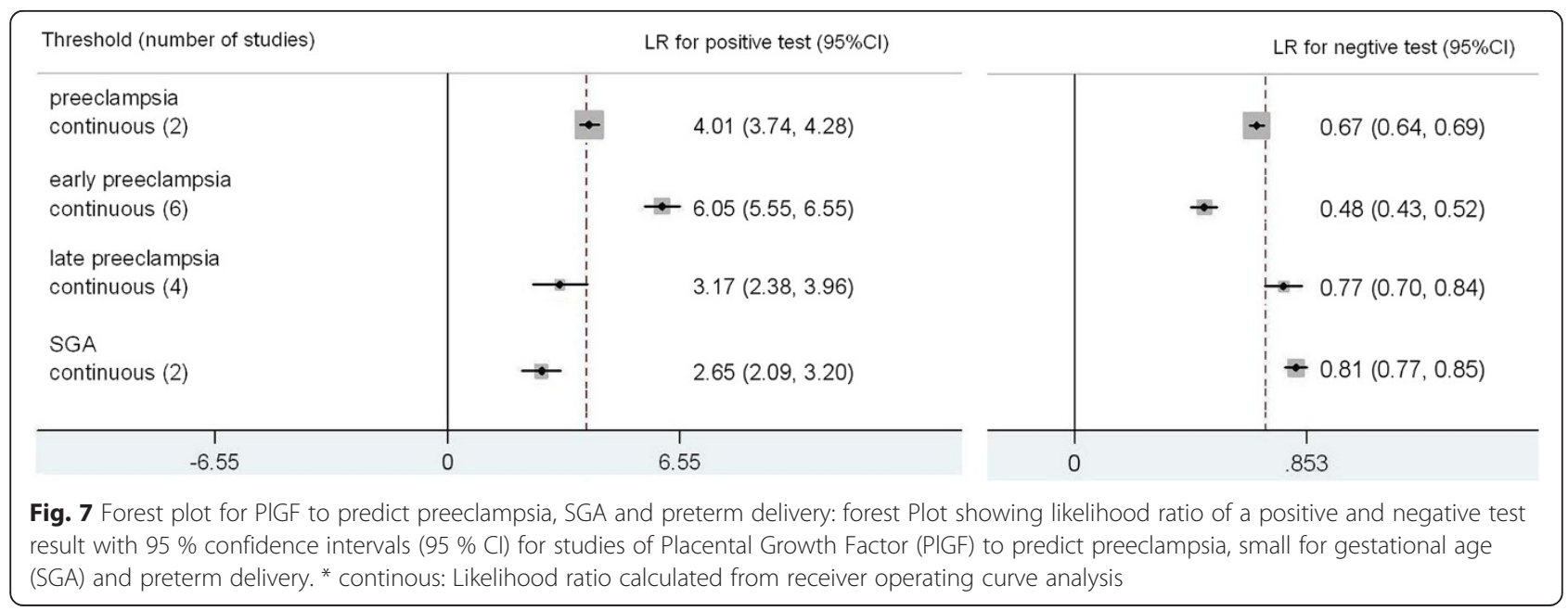




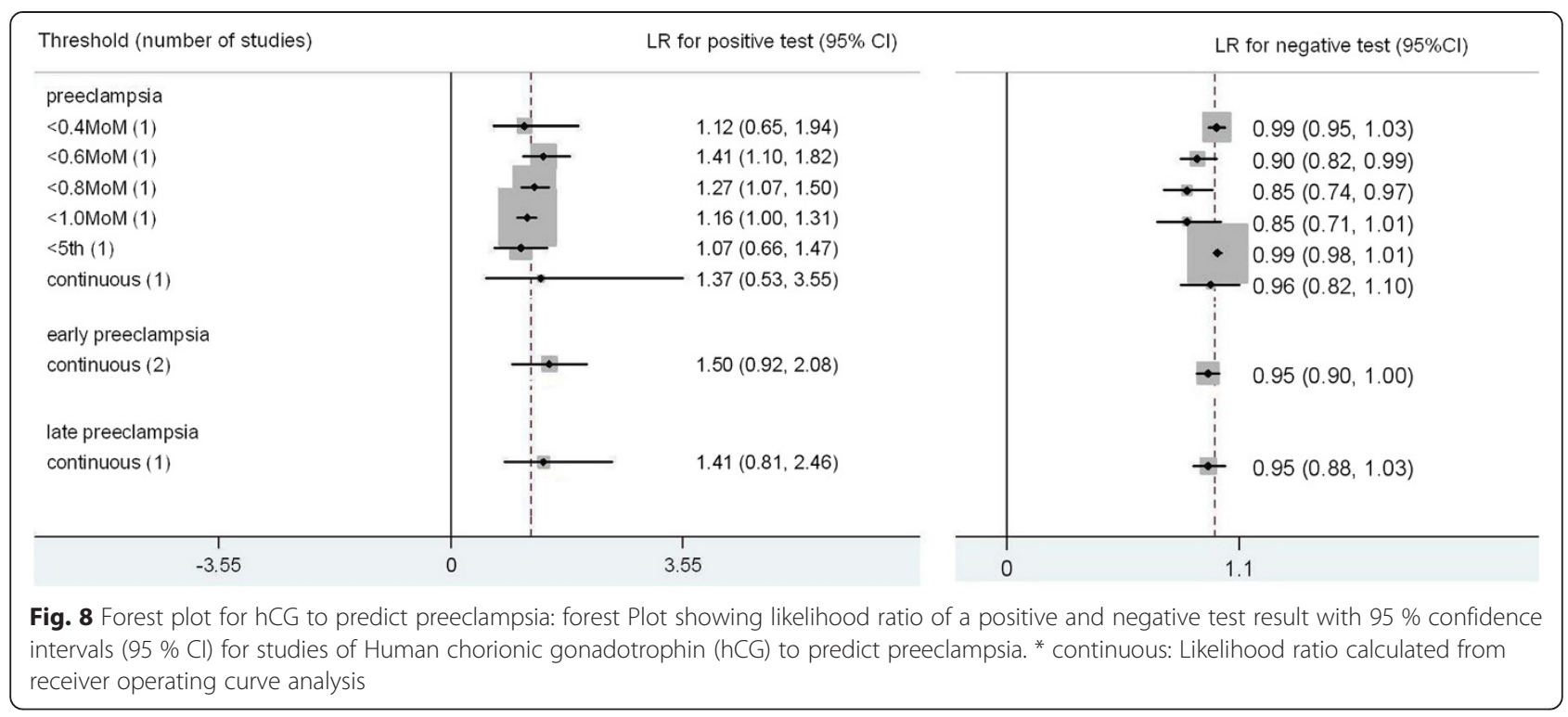

predictor was PP13 while PAPPA $<0.3 \mathrm{MoM}$ was the best predictor of preterm delivery $<34$ weeks.

The predict value of first trimester analytes is not worse compare to that of the second trimester markers. Previous studies show in the second trimester, the most accurate predictor of hCG for preeclampsia was hCG > 2.0 MoM, with LR+ 2.45 (1.57, 3.84), LR- 0.89 (0.83, 0.96); for SGA was hCG > 2.0 MoM, with LR+ 1.74 (1.48, 2.04), LR-0.95 $(0.93,0.96)$. The most accurate predictor of PAPPA for preeclampsia was PAPP-A $<5^{\text {th }}$ centile, with $\mathrm{LR}+2.10$ $(1.57,2.81)$, LR- $0.95(0.93,0.98)$; for SGA was PAPP-A $<1^{\text {st }}$ centile; LR+ 3.50 (2.53, 4.82), LR- $0.98(0.97,0.99)$. On the other hand, our meta-analysis shows the most accurate predictor of hCG for preeclampsia was hCG < $0.6 \mathrm{MoM}$;
LR+ 1.41 (1.10, 1.82), LR- 0.90 (0.82, 0.99), for SGA was calculated from receiver operating curve analysis; LR+ 3.44 (3.26, 3.63), LR-0.73 (0.71, 0.74). The most accurate predictor of PAPPA for preeclampsia was PAPPA < 0.4 MoM; LR+ 2.17 (1.48, 3.17), LR- 0.91 (0.85, $0.97)$, for SGA was PAPPA $<1^{\text {st }}$ centile; $L R+3.59$ (2.77, $4.40)$, LR- $0.98(0.97,0.98)$. A possible explanation for the apparent difference of hCG change between first trimester and second trimester is that the low levels at first trimester are the consequence of impaired placentation and smaller placental mass, whereas the high levels in the second trimester may be the result of 'leakage' or hypoperfusionrelated stimulation of production of this hormone [47]. Although the symptoms of preeclampsia and FGR generally

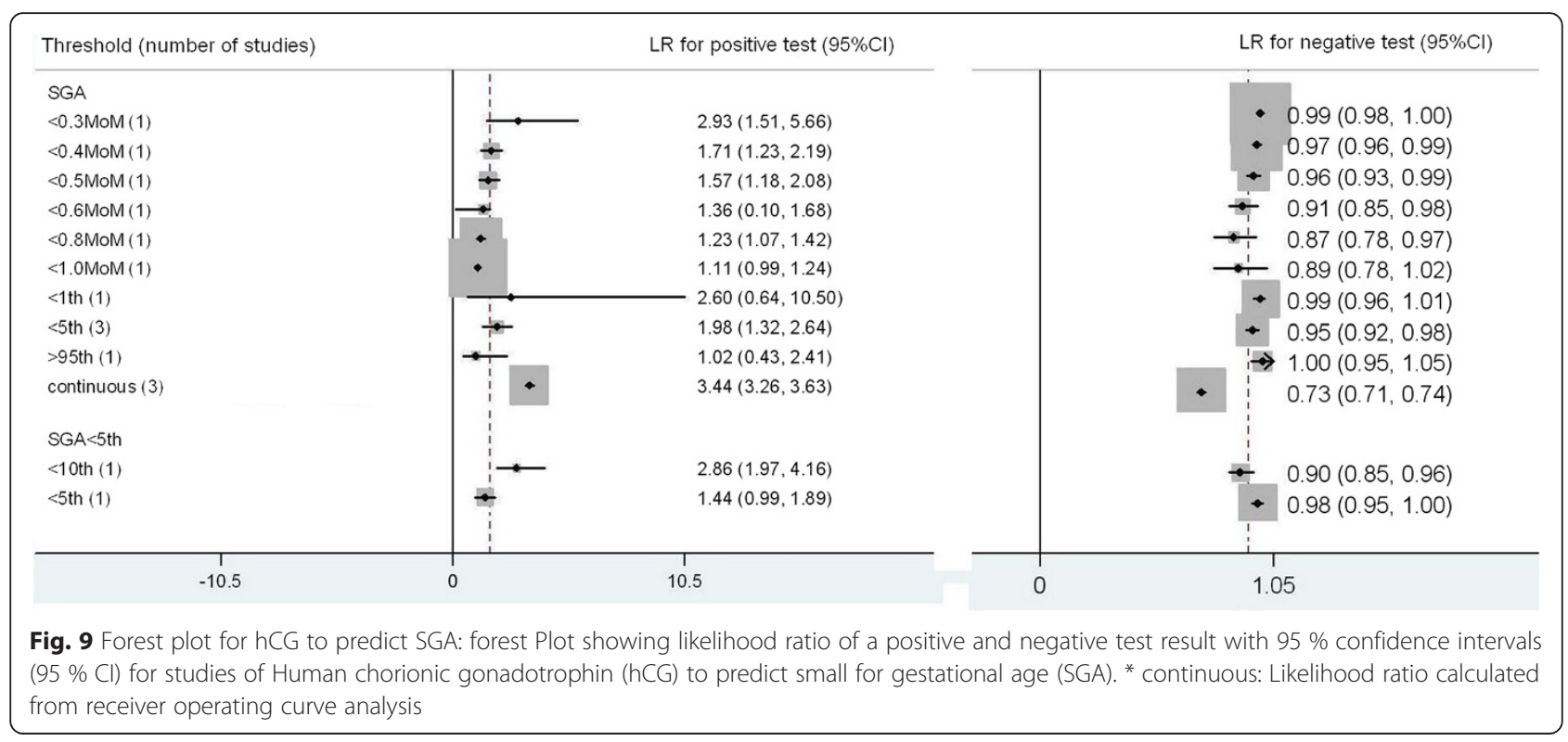




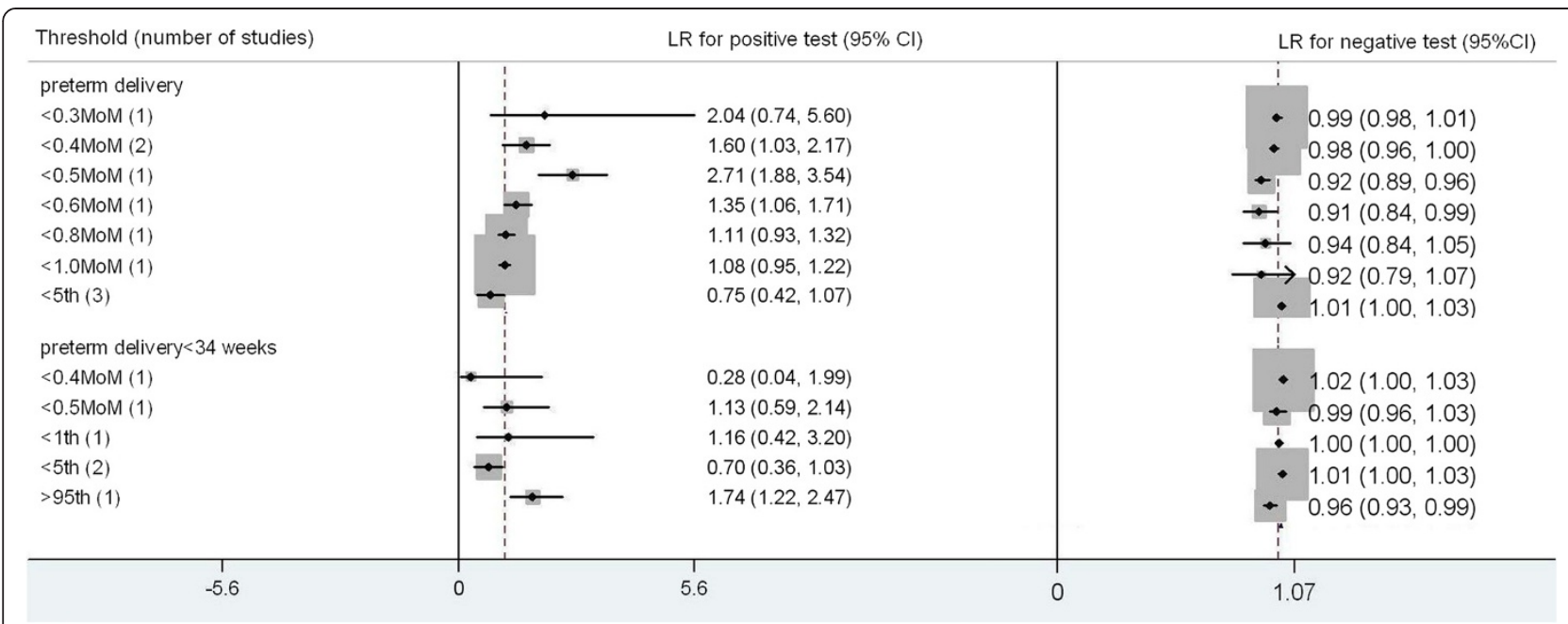

Fig. 10 Forest plot for hCG to predict prelivery: forest Plot showing likelihood ratio of a positive and negative test result with $95 \%$ confidence intervals $(95 \% \mathrm{Cl}$ ) for studies of Human chorionic gonadotrophin (hCG) to predict preterm delivery

manifest in the second to third trimester of pregnancy, their underlying pathology takes place in the first trimester. One possible reason why preventive strategies have proven very disappointing at present is that the proposed interventions have commenced in the mid to late second trimester, when the underlying placental dysfunction may already be established. Earlier assessment before the establishment of placental dysfunction may have the potential to improve predictive value for clinical practice. With the increased use of first-trimester screening for Down syndrome, there is the opportunity to 'piggy back' screening tests for preeclampsia, FGR and preterm delivery onto existing tests.

As preeclampsia and SGA are diseases with relatively low prevalence, a clinically useful test would need to have a high positive LR $(>10)$ and low negative LR $(<0.10)$ [48]. From the results of this review it is unlikely that any first trimester serum screening marker in isolation will provide this. Future research should thus concentrate in two areas. The first is to improve the knowledge of the biological mechanisms for the abnormal clinical tests by focusing on the exact placental pathology resulting in the changes seen in preeclampsia, FGR and preterm delivery. Preliminary findings suggest that genomic studies can improve our understanding of the early pathophysiology of preeclampsia/FGR/preterm delivery at the molecular level. It is hoped that proteomics, metabolomics, and other techniques will allow us to provide potential targets for the development of biomarkers with high enough predictive and prognostic information to be translated into clinical practice. Secondly, future research should attempt to improve the predictive value by combining Doppler sonography, different maternal serum analytes and clinical characteristics. The use of multiple parameters increases the specificity and sensitivity of the screening possibly because they reflect different pathways to the disease process, with abnormal Doppler reflecting the inadequate trophoblastic invasion of the maternal spiral arteries and abnormal biomarkers demonstrating the dysregulated secretory activity by the trophoblasts. However, some studies showed no additive effect of combining different markers, likely secondary to correlation between the markers (such as ADAM12 and PAPP-A, sFlt-1 and sEng) [47]. Sequential measurements of markers might also improve the risk assessment as individual changes from the first to second trimesters have been shown to occur in preeclampsia and FGR.

Our result also showed the detection rate of first trimester serum markers for early preeclampsia is better than that for late preeclampsia. This disparity may result from different etiologies between early and late preeclampsia. Early preeclampsia is said to be associated with inadequate and incomplete trophoblast invasion of maternal spiral arteries, and is often complicated with a fetal growth restriction. In contrast, the late onset type of preeclampsia is often related to enlarged placental mass or surface (diabetes, multiple pregnancies, anemia, high altitude). It often shows normal or only slightly altered behavior of the uterine spiral arteries and thus no changes in the blood flow of the umbilical arteries. Fetus with late onset preeclampsia often shows no signs of any growth restriction [49]. Since abnormal concentration of serum markers in the first trimester is caused by intrinsic alteration of the villous trophoblast, it is reasonable that predictive value would be poorer for late onset preeclampsia with normal or only slightly altered trophoblast invasion in the first trimester.

The strength of the study includes generally sufficient quality and a quality assessment of studies based on recognized criteria. However, there are still some limitations. First, there is large discordance in reports of cutoff 
points, thus, a formal meta-analysis with estimated overall relative risks was not feasible. Secondly, the number of studies for some cutoffpoints is so small that they lead to some contradictive results. For example, our analysis shows the best predictor for preterm delivery was hCG $<0.5$ MoM while the best predictor for preterm delvery $<34$ weeks is a hCG $>95^{\text {th }}$ centile. This odd result is probably due to the small numbers of studies since there is only one study for each threshold. Clearly large scale studies are needed for more reliable evaluation. Thirdly, all of the studies we selected are population of low risk so we are unable to perform a sub analysis. We didn't choose the population of high risk since there are few studies on it. More studies are needed to analyse predictive accuracy by the type of population.

\section{Conclusion}

First trimester screening analytes have low predictive accuracy for pre-eclampsia, SGA and preterm delivery. However, the predict value of first trimester analytes is not worse compare to that of the second trimester markers. They may be useful in prediction when combined with other tests. Early pathophysiology of preeclampsia/FGR/ preterm delivery should be studied to develop biomarkers with high enough predictive and prognostic information to be translated into clinical practice.

\section{Abbreviations}

PAPP-A: Pregnancy- associated plasma protein-A; hCG: Human chorionic gonadotropin; PIGF: Placental growth factor; PP13: Placental protein 13; SGA: Small for gestational age; LR: Likelihood ratio.

\section{Competing interests}

The authors declare that they have no competing interests.

\section{Authors' contributions}

YD and FZ independently selected the articles, and independently extracted data on study characteristics, quality and results. YZ designed the study, performed the statistical analysis, and draft the manuscript. All authors read and approved the final manuscript.

Received: 13 December 2014 Accepted: 4 August 2015

Published online: 25 August 2015

\section{References}

1. Ray JG, Vermeulen MJ, Schull MJ, Redelmeier DA. Cardiovascular health after maternal placental syndromes (CHAMPS): population-based retrospective cohort study. Lancet. 2005;366(9499):1797-803.

2. Barker DJ. Adult consequences of fetal growth restriction. Clin Obstet Gynecol. 2006;49(2):270-83.

3. Gluckman PD, Hanson MA, Cooper C, Thornburg KL. Effect of in utero and early-life conditions on adult health and disease. N Engl I Med. 2008:359(1):61-73.

4. Dugoff L, Hobbins JC, Malone FD, Porter TF, Luthy D, Comstock CH, et al. First-trimester maternal serum PAPP-A and free-beta subunit human chorionic gonadotropin concentrations and nuchal translucency are associated with obstetric complications: a population-based screening study (the FASTER Trial). Am J Obstet Gynecol. 2004;191(4):1446-51.

5. Poon LC, Nekrasova E, Anastassopoulos P, Livanos P, Nicolaides KH. First-trimester maternal serum matrix metalloproteinase-9 (MMP-9) and adverse pregnancy outcome. Prenat Diagn. 2009;29(6):553-9.
6. Pilalis A, Souka AP, Antsaklis P, Daskalakis G, Papantoniou N, Mesogitis S, et al. Screening for pre-eclampsia and fetal growth restriction by uterine artery Doppler and PAPP-A at 11-14 weeks' gestation. Ultrasound Obstet Gynecol. 2007;29(2):135-40.

7. LA Ong CT, Spencer K, Munim S, Nicolaides KH. First-trimester maternal serum free beta-human chorionic gonadotropin and pregnancy associated plasma protein-A as predictors of pregnancy complications. Bjog-an International Journal of Obstetrics and Gynaecology. 2000;107:1265-70.

8. Spencer K, Cowans NJ, Chefetz I, Tal J, Meiri H. First-trimester maternal serum PP-13, PAPP-A and second-trimester uterine artery Doppler pulsatility index as markers of pre-eclampsia. Ultrasound Obstet Gynecol. 2007;29(2):128-34.

9. Hedley PL, Placing S, Wojdemann K, Carlsen AL, Shalmi AC, Sundberg K, et al. Free leptin index and PAPP-A: a first trimester maternal serum screening test for pre-eclampsia. Prenat Diagn. 2010;30(2):103-9.

10. Smith GC, Stenhouse EJ, Crossley JA, Aitken DA, Cameron AD, Connor JM. Early pregnancy levels of pregnancy-associated plasma protein a and the risk of intrauterine growth restriction, premature birth, preeclampsia, and stillbirth. J Clin Endocrinol Metab. 2002;87(4):1762-7.

11. Jenni K, Ranta KR. Jarkko Romppanen, Kari Pulkki, Seppo Heinonen Decreased PAPP-A is associated with preeclampsia, premature delivery and small for gestational age infants but not with placental abruption. Eur J Obstet Gynecol Reprod Biol. 2011;157(2011):48-52.

12. Wortelboer EJ, Koster MP, Cuckle HS, Stoutenbeek PH, Schielen PC, Visser GH. First-trimester placental protein 13 and placental growth factor: markers for identification of women destined to develop early-onset pre-eclampsia. BJOG. 2010;117(11):1384-9.

13. Audibert F, Boucoiran I, An N, Aleksandrov N, Delvin E, Bujold E, et al. Screening for preeclampsia using first-trimester serum markers and uterine artery Doppler in nulliparous women. Am J Obstet Gynecol. 2010;203(4):e1-8.

14. Akolekar R, Zaragoza E, Poon LCY, Pepes S, Nicolaides KH. Maternal serum placental growth factor at $11+0$ to $13+6$ weeks of gestation in the prediction of pre-eclampsia. Ultrasound Obstet Gynecol. 2008;32(6):732-9.

15. Akolekar R, Syngelaki A, Sarquis R, Zvanca M, Nicolaides KH. Prediction of early, intermediate and late pre-eclampsia from maternal factors, biophysical and biochemical markers at 11-13 weeks. Prenat Diagn. 2011;31(1):66-74.

16. Poon LCY, Maiz N, Valencia C, Plasencia W, Nicolaides KH. First-trimester maternal serum pregnancy-associated plasma protein-A and pre-eclampsia. Ultrasound Obstet Gynecol. 2009;33(1):23-33.

17. Foidart JM, Munaut C, Chantraine F, Akolekar R, Nicolaides KH. Maternal plasma soluble endoglin at 11-13 weeks' gestation in pre-eclampsia. Ultrasound Obstet Gynecol. 2010;35(6):680-7.

18. Keikkala E, Vuorela P, Laivuori H, Romppanen J, Heinonen S, Stenman UH. First trimester hyperglycosylated human chorionic gonadotrophin in serum - a marker of early-onset preeclampsia. Placenta. 2013;34(11):1059-65.

19. Kuc S, Koster MP, Franx A, Schielen PC, Visser GH. Maternal characteristics, mean arterial pressure and serum markers in early prediction of preeclampsia. PLoS One. 2013;8(5), e63546.

20. Akolekar R, Syngelaki A, Poon L, Wright D, Nicolaides KH. Competing risks model in early screening for preeclampsia by biophysical and biochemical markers. Fetal Diagn Ther. 2013;33(1):8-15.

21. Moslemi Zadeh N, Naghshvar F, Peyvandi S, Gheshlaghi P, Ehetshami S. PP13 and PAPP-A in the First and Second Trimesters: Predictive Factors for Preeclampsia? ISRN Obstet Gynecol. 2012;2012:263871.

22. Goetzinger KR, Singla A, Gerkowicz S, Dicke JM, Gray DL, Odibo AO. Predicting the risk of pre-eclampsia between 11 and 13 weeks' gestation by combining maternal characteristics and serum analytes, PAPP-A and free beta-hCG. Prenat Diagn. 2010;30(12-13):1138-42.

23. Kirkegaard I, Henriksen TB, Uldbjerg N. Early fetal growth, PAPP-A and free beta-hCG in relation to risk of delivering a small-for-gestational age infant. Ultrasound Obstet Gynecol. 2011;37(3):341-7.

24. Pihl K, Larsen T, Krebs L, Christiansen M. First trimester maternal serum PAPP-A, beta-hCG and ADAM12 in prediction of small-for-gestational-age fetuses. Prenat Diagn. 2008;28(12):1131-5.

25. Krantz D, Goetzl L, Simpson JL, Thom E, Zachary J, Hallahan TW, et al. Association of extreme first-trimester free human chorionic gonadotropinbeta, pregnancy-associated plasma protein $\mathrm{A}$, and nuchal translucency with intrauterine growth restriction and other adverse pregnancy outcomes. Am J Obstet Gynecol. 2004;191(4):1452-8.

26. Kwik M, Morris J. Association between first trimester maternal serum pregnancy associated plasma protein-A and adverse pregnancy outcome. Aust N Z J Obstet Gynaecol. 2003;43(6):438-42. 
27. Leung TY, Sahota DS, Chan LW, Law LW, Fung TY, Leung TN, et al. Prediction of birth weight by fetal crown-rump length and maternal serum levels of pregnancy-associated plasma protein-A in the first trimester. Ultrasound Obstet Gynecol. 2008;31(1):10-4.

28. Goetzinger KR, Singla A, Gerkowicz S, Dicke JM, Gray DL, Odibo AO. The efficiency of first-trimester serum analytes and maternal characteristics in predicting fetal growth disorders. Am J Obstet Gynecol. 2009;201(4):e1-6.

29. Karagiannis G, Akolekar R, Sarquis R, Wright D, Nicolaides KH. Prediction of small-for-gestation neonates from biophysical and biochemical markers at 11-13 weeks. Fetal Diagn Ther. 2011:29(2):148-54.

30. Montanari L, Alfei A, Albonico G, Moratti R, Arossa A, Beneventi F, et al. The impact of first-trimester serum free beta-human chorionic gonadotropin and pregnancy-associated plasma protein A on the diagnosis of fetal growth restriction and small for gestational age infant. Fetal Diagn Ther. 2009;25(1):130-5.

31. Plasencia W, Akolekar R, Dagklis T, Veduta A, Nicolaides KH. Placental volume at 11-13 weeks' gestation in the prediction of birth weight percentile. Fetal Diagn Ther. 2011;30(1):23-8.

32. Poon LC, Zaragoza E, Akolekar R, Anagnostopoulos E, Nicolaides KH. Maternal serum placental growth factor (PIGF) in small for gestational age pregnancy at $11(+0)$ to $13(+6)$ weeks of gestation. Prenat Diagn. 2008;28(12):1110-5.

33. Cowans NJ, Spencer K. First-trimester ADAM12 and PAPP-A as markers for intrauterine fetal growth restriction through their roles in the insulin-like growth factor system. Prenat Diagn. 2007;27(3):264-71.

34. Pihl K, Larsen T, Laursen I, Krebs L, Christiansen M. First trimester maternal serum pregnancy-specific beta-1-glycoprotein (SP1) as a marker of adverse pregnancy outcome. Prenat Diagn. 2009;29(13):1256-61.

35. Lain SJ, Algert CS, Tasevski V, Morris JM, Roberts CL. Record linkage to obtain birth outcomes for the evaluation of screening biomarkers in pregnancy: a feasibility study. BMC Med Res Methodol. 2009;9:48.

36. Poon LC, Karagiannis G, Staboulidou I, Shafiei A, Nicolaides KH. Reference range of birth weight with gestation and first-trimester prediction of small-for-gestation neonates. Prenat Diagn. 2011;31(1):58-65.

37. Dane B, Dane C, Kiray M, Cetin A, Koldas M, Erginbas M. Correlation between first-trimester maternal serum markers, second-trimester uterine artery doppler indices and pregnancy outcome. Gynecol Obstet Invest. 2010;70(2):126-31.

38. Goetzinger KR, Cahill AG, Kemna J, Odibo L, Macones GA, Odibo AO. First-trimester prediction of preterm birth using ADAM12, PAPP-A, uterine artery Doppler, and maternal characteristics. Prenat Diagn. 2012;32(10):1002-7.

39. Stout MJ, Goetzinger KR, Tuuli MG, Cahill AG, Macones GA, Odibo AO. First trimester serum analytes, maternal characteristics and ultrasound markers to predict pregnancies at risk for preterm birth. Placenta. 2013;34(1):14-9.

40. Barrett SL, Bower C, Hadlow NC. Use of the combined first-trimester screen result and low PAPP-A to predict risk of adverse fetal outcomes. Prenat Diagn. 2008;28(1):28-35.

41. Nicolaides KH, Bindra R, Turan OM, Chefetz I, Sammar M, Meiri H, et al. A novel approach to first-trimester screening for early pre-eclampsia combining serum PP-13 and Doppler ultrasound. Ultrasound Obstet Gynecol. 2006;27(1):13-7.

42. Romero R, Kusanovic JP, Than NG, Erez O, Gotsch F, Espinoza J, et al. First-trimester maternal serum PP13 in the risk assessment for preeclampsia. Am J Obstet Gynecol. 2008;199(2):e1-e11.

43. Khalil A, Cowans NJ, Spencer K, Goichman S, Meiri H, Harrington K First trimester maternal serum placental protein 13 for the prediction of pre-eclampsia in women with a priori high risk. Prenat Diagn. 2009;29(8):781-9.

44. Akolekar R, Syngelaki A, Beta J, Kocylowski R, Nicolaides KH. Maternal serum placental protein 13 at 11-13 weeks of gestation in preeclampsia. Prenat Diagn. 2009;23.

45. Chafetz I, Kuhnreich I, Sammar M, Tal Y, Gibor Y, Meiri H, et al. First-trimester placental protein 13 screening for preeclampsia and intrauterine growth restriction. Am J Obstet Gynecol. 2007;197(1):e1-7.

46. Odibo AO, Zhong Y, Goetzinger KR, Odibo L, Bick JL, Bower CR, et al. First-trimester placental protein 13, PAPP-A, uterine artery Doppler and maternal characteristics in the prediction of pre-eclampsia. Placenta. 2011;32(8):598-602.
47. Zhong Y, Tuuli M, Odibo AO. First-trimester assessment of placenta function and the prediction of preeclampsia and intrauterine growth restriction. Prenat Diagn. 2010;30(4):293-308.

48. Deeks JJ, Altman DG. Diagnostic tests 4: likelihood ratios. BMJ. 2004;329(7458):168-9.

49. Huppertz B. Placental origins of preeclampsia: challenging the current hypothesis. Hypertension. 2008;51(4):970-5.

\section{Submit your next manuscript to BioMed Central and take full advantage of:}

- Convenient online submission

- Thorough peer review

- No space constraints or color figure charges

- Immediate publication on acceptance

- Inclusion in PubMed, CAS, Scopus and Google Scholar

- Research which is freely available for redistribution 